\title{
Avaliação histomorfométrica do parênquima testicular de ratos adultos tratados com diferentes doses de ivermectina
}

\author{
[Histomorphometric evaluation of testicular parenchyma of adult rats treated \\ with different dosages of ivermectin] \\ C.S. Moura ${ }^{1}$, M.M.P.Guerra ${ }^{2}$, V.A. Silva Júnior ${ }^{3 *}$, C.G.C. Silva ${ }^{3}$, F.M. Caju ${ }^{3}$, L.C. Alves ${ }^{2}$ \\ ${ }^{1}$ Aluna de pós-graduação - UFRPE \\ ${ }^{2}$ Departamento de Medicina Veterinária - UFRPE \\ ${ }^{3}$ Departamento de Morfologia e Fisiologia Animal - UFRPE \\ Rua Dom Manuel de Medeiros, s/n \\ 52171-900 - Recife, PE
}

\begin{abstract}
RESUMO
Avaliou-se o efeito da ivermectina sobre o parênquima testicular através da produção espermática diária e da eficiência da espermatogênese em ratos Wistar adultos tratados com diferentes dosagens $(200,400$ e $600 \mu \mathrm{g} / \mathrm{kg}$ ). Pela avaliação histomorfométrica, o parênquima testicular e o processo espermatogênico dos ratos Wistar não sofreram qualquer efeito deletério da aplicação de ivermectina, o que foi confirmado pela manutenção da produção espermática diária por testículo, pelo rendimento intrínseco da espermatogênese $(\mathrm{PED} / \mathrm{g} / \mathrm{t})$ e pela manutenção da estrutura do parênquima testicular. Com base nos resultados quantitativos e qualitativos da espermatogênese, é possível concluir que a ivermectina não tem efeito tóxico-degenerativo sobre o parênquima testicular de ratos Wistar adultos.
\end{abstract}

Palavras-chave: rato, espermatogênese, ivermectina

\begin{abstract}
The aim of this work was to evaluate the ivermectin effect on the testicular parenchyma through the daily spermatic production and the efficiency of the spermatogenesis in adult Wistar rats treated with different dosages (200, 400 and $600 \mu \mathrm{g} / \mathrm{kg})$ of ivermectin. Based on the histomorfometric evaluation, ivermectin had no deleterious effect on the testicular parenchyma and spermatogesis, which one was confirmed through the maintenance of the daily spermatic input and intrinsic income of spermatogenesis $(P E D / g / t)$, as well as by the maintenance of the testicular parenchyma structure. Based on the quantitative and qualitative results of spermatogenesis, it is possible to conclude that ivermectin does not have toxicdegenerative effect on the testicular parenchyma of adult Wistar rats.
\end{abstract}

Keywords: rat, spermatogenesis, ivermectin

Recebido em 23 de fevereiro de 2005

Aceito em 17 de julho de 2006

*Autor para correspondência (corresponding author)

E-mail: valdemiro.amaro@bol.com.br 


\section{INTRODUÇ̃̃O}

As ivermectinas constituem um grupo de lactonas macrocíclicas, isoladas a partir do Streptomyces avermitilis, que possuem potente atividade parasiticida em inúmeras espécies animais, inclusive em humanos (Greene et al., 1985; Cupp et al., 1986). O mecanismo de ação dessa droga resulta de sua ligação a receptores de alta afinidade, os quais promovem abertura dos canais de cloro, hiperpolarização celular em neurônios e músculos, acarretando morte do organismo (Kass et al., 1980;1984). A baixa afinidade de receptores no sistema nervoso central de mamíferos (Lankas et al., 1989) e a relativa inabilidade da ivermectina em atravessar a barreira hematoencefálica tornam esses animais pouco sensíveis aos prováveis efeitos tóxicos dessa droga.

Em biotérios, é de fundamental importância o controle das ecto e endoparasitoses, uma vez que podem interferir na análise dos resultados obtidos experimentalmente ou intensificar os seus efeitos, como conseqüência do estresse (Marques, 2002).

Visando ao controle de ectoparasitas, em ratos e camundongos, a ivermectina pode ser utilizada através de sua aplicação subcutânea na dosagem de $200 \mu \mathrm{g}$ a $400 \mu \mathrm{g} / \mathrm{kg}$ de peso corporal (Baumans et al., 1988; Flecknell, 1994); por via oral, na mesma dose com intervalo de dez dias ou através da administração tópica de solução de ivermectina diluída em 1:100 de água e propilenoglicol, fracionada em três aplicações (Baumans et al., 1988). Em várias espécies de animais de laboratório, os efeitos colaterais provocados pela administração oral de altas doses de ivermectina podem resultar em sinais de neurotoxicidade (Nessel et al., 1983).

Lankas et al. (1989) não constataram efeito tóxico dessa droga sobre a idade ao primeiro acasalamento, a duração da gestação e a mortalidade em ratos neonatos, mas observaram sinais de toxicidade caracterizados por perda de peso e mortalidade durante a lactação.

Apesar de a ivermectina ser utilizada no controle de ecto e endoparasitos, em ratos e camundongos, ainda não foi avaliada a ação desse fármaco sobre parâmetros produtivos e histológicos do testículo. Objetivou-se neste trabalho estudar os efeitos da administração de ivermectina sobre a estrutura do parênquima testicular, a produção espermática diária e a eficiência do processo espermatogênico em ratos Wistar adultos.

\section{MATERIAL E MÉTODOS}

Foram utilizados 20 ratos adultos, Wistar (Rattus norvegicus, var. albinus) pertencentes ao biotério da Área de Fisiologia do DMFA/UFRPE, os quais foram mantidos em ambiente com temperatura de $23 \pm 1^{\circ} \mathrm{C}$, em ciclo claro-escuro de 12 horas. Água e ração própria para roedores ${ }^{1}$ foram oferecidas ad libitum durante o período experimental. Cinco ratos foram escolhidos por amostragem não probabilística de conveniência (Reis, 2003) e submetidos aos diversos tratamentos, de acordo com o grupo experimental: A) grupo-controle: administração de $0,2 \mathrm{ml}$ de solução físiológica $(0,9 \%)$ de cloreto de sódio; B) grupo tratado com $200 \mu \mathrm{g} / \mathrm{kg}$ de ivermectina $^{2}$; C) grupo tratado com $400 \mu \mathrm{g} / \mathrm{kg}$ de ivermectina e D) grupo tratado com $600 \mu \mathrm{g} / \mathrm{kg}$ de ivermectina.

Os tratamentos foram realizados durante um período de 28 dias, em cinco aplicações por via subcutânea, nos dias $0,7,14,21$ e 28. A pesagem de todos os animais foi realizada semanalmente, durante os 35 dias do experimento, para acompanhamento do peso corporal e cálculo das doses de ivermectina. Aos 35 dias do período experimental, os ratos de cada grupo foram heparinizados (130UI/100g de peso corporal), anestesiados por injeção intraperitonial de tiopental sódico ${ }^{3}(30 \mathrm{mg} / \mathrm{kg})$ e submetidos à perfusão intracardíaca com solução fisiológica de $\mathrm{NaCl}$ a $0,9 \%$, acrescida de heparina sódica ${ }^{4}$ (500UI/1) e nitroprussiato ${ }^{5}(100 \mathrm{mg} / \mathrm{l})$, por um tempo entre cinco e 10 minutos. Após a lavagem do sistema vascular, os animais foram perfundidos com solução fixadora de glutaraldeído ${ }^{6}$ a $4 \%$, em tampão fosfato de sódio (pH7,2 e $0,01 \mathrm{M})$, durante 25 minutos.

\footnotetext{
${ }^{1}$ Labina, Purina - Paulínia, Brasil

${ }^{2}$ Lab. Ourofino - Ribeiro Preto, Brasil

${ }^{3}$ Roche - São Paulo, Brasil

${ }^{4}$ Akzo Organon Teknika - Boxtel, Holanda

${ }^{5}$ Sigma - Saint Louis, USA

${ }^{6}$ Vetec - Rio de Janeiro, Brasil
} 
Os testículos foram removidos, pesados e seccionados em fragmentos de até $2 \mathrm{~mm}$ de espessura, os quais foram submetidos a refixação na mesma solução de perfusão. Para avaliação em microscopia de luz, os fragmentos foram processados rotineiramente para inclusão em resina plástica à base de glicol-metacrilato ${ }^{7}$, foram feitos cortes de $4 \mu \mathrm{m}$ de espessura e, em seguida, corados com azul de toluidina/borato de sódio a $1 \%$.

O diâmetro tubular e a altura do epitélio foram medidos com ocular micrométrica ${ }^{8}$ (100X) calibrada com micrômetro padrão. Vinte perfis tubulares redondos ou arredondados foram medidos, e a média foi determinada para cada rato. A altura do epitélio foi obtida nos mesmos túbulos utilizados para medida de diâmetro. Os dados morfométricos da composição dos testículos foram obtidos usando contagem de pontos por alocação sistemática aleatória de uma gratícula integradora com 441 pontos de intersecção sobre o parênquima testicular, com aumento de 400X. Aproximadamente 6600 pontos foram contados para cada animal. O volume de cada componente do testículo foi estabelecido a partir do produto entre densidade volumétrica (\%) e de volume líquido do testículo (peso líquido do testículo). A gravidade específica do tecido testicular foi considerada como 1.0, para os cálculos morfométricos subseqüentes. Para se ter uma medida exata do volume líquido do testículo, $6,5 \%$ da cápsula desse foi extraída do seu peso (Russel e França, 1995). O comprimento total dos túbulos seminíferos (metros) foi obtido ao dividir o volume do túbulo por $\pi \mathrm{R}^{2}$ (França et al., 2000).

Os números de espermatócitos I em estágio de pré-leptóteno e paquíteno, de espermátides arredondadas e de nucléolos das células de Sertoli foram contados nos túbulos seminíferos redondos, em corte transversal, no estágio VII do ciclo do epitélio seminífero.

A população celular obtida por secção transversal de cinco túbulos seminíferos no estágio VII foi corrigida pela espessura do corte histológico e pelo diâmetro do núcleo, de acordo com Abercrombie (1946), modificado por Amann e Almquist (1962). Os nucléolos das

\footnotetext{
${ }^{7}$ Leica - Heildeberg, Alemanha

${ }^{8}$ Zeiss - Heidenheim, Alemanha
}

células de Sertoli foram utilizados para obtenção dos números corrigidos desse tipo celular por secção transversal de túbulo seminífero devido à forma irregular do núcleo dessa célula. A partir destas contagens corrigidas, foi obtida a razão entre espermátides arredondadas e células de Sertoli (índice de célula de Sertoli = ICS), por secção transversal de túbulo seminífero (França e Russel, 1998). A produção espermática diária por testículo e por grama de testículo foi obtida de acordo com Russell et al. (1990) e Rocha et al. (1999): PED = total de células de Sertoli por testículo x ICS x freqüência relativa do estágio VII (\%)/duração do estágio VII (dias). Em que: freqüência relativa do estágio VII $(\%)=18,1$ (Russel et al., 1990) e duração do estágio VII $($ dias $)=2,33$.

Os dados biométricos e histométricos foram expressos em média \pm desvio padrão. Foram realizadas as análises de variância entre os grupos (ANOVA) e o teste de Tukey, com nível de significância de $\mathrm{P}<0,05$.

\section{RESULTADOS E DISCUSSÃO}

$\mathrm{Na}$ Tab. 1 é possível observar que não houve diferença $(\mathrm{P}>0,05)$ no peso corporal dos ratos entre os grupos experimentais. $\mathrm{O}$ peso corporal dos animais dos diferentes grupos variou de 455,4 a 521,4g. De acordo com Harkness e Wagner (1993), o peso corporal de ratos machos adultos varia de 450 a $520 \mathrm{~g}$ evidenciando que os animais utilizados neste experimento encontravam-se dentro do padrão biométrico esperado para a espécie, além de constatar que a ivermectina não influenciou no peso corporal dos animais.

Os pesos bruto e líquido dos testículos dos animais do grupo $C$ foram maiores $(P<0,05)$ em relação aos dos grupos $\mathrm{A}, \mathrm{B}, \mathrm{D}$ e $\mathrm{A}, \mathrm{D}$ respectivamente (Tab. 1 e 2). Para o peso do epidídimo, não houve diferença entre os grupos (Tab. 1).

O índice gonadossomático (IGS), que determina o percentual de massa corpórea alocada no testículo, teve redução significativa $(\mathrm{P}<0,05)$ nos animais do grupo D em relação aos do grupo B (Tab. 1). Fato justificado pelo aumento médio do peso corporal dos animais do grupo $\mathrm{D}$, porém o peso testicular bruto não acompanhou o 
desenvolvimento observado nos ratos dos demais grupos experimentais. Salienta-se também que, apesar de não significativo $(\mathrm{P}>0,05)$, o peso corporal dos animais do grupo $\mathrm{B}$ apresentou tendência de redução, o que influenciou no aumento do IGS dos animais tratados com a menor dose de ivermectina.

Nos resultados relacionados ao diâmetro tubular, não se verificou diferença entre os grupos, porém, em relação à altura do epitélio seminífero, os grupos $\mathrm{C}$ e $\mathrm{D}$ foram menores $(\mathrm{P}<0,05)$ quando comparados ao grupo-controle
(Tab. 2). Segundo Sinha-Hikim et al. (1989), o diâmetro tubular possui correlação positiva com a atividade espermatogênica. Ratos adultos Sprague-Dawley possuem diâmetro tubular

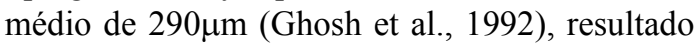
semelhante ao observado no diâmetro tubular dos animais-controle desse experimento. Além disso, como não houve diferença no diâmetro tubular entre os grupos experimentais, é possível afirmar que a ivermectina não influenciou nesta característica morfométrica testicular nem na atividade espermatogênica.

Tabela 1. Parâmetros biométricos de ratos Wistar adultos, controle e tratados com diferentes doses de ivermectina aos 90 dias de idade

\begin{tabular}{lcccc}
\hline \multirow{2}{*}{ Características } & \multicolumn{4}{c}{ Grupos experimentais } \\
\cline { 2 - 5 } & $\begin{array}{c}\mathrm{A}(\text { controle }) \\
(\mathrm{n}=5)\end{array}$ & $\begin{array}{c}\mathrm{B}(200 \mu \mathrm{g} / \mathrm{Kg}) \\
(\mathrm{n}=5)\end{array}$ & $\begin{array}{c}\mathrm{C}(400 \mu \mathrm{g} / \mathrm{Kg}) \\
(\mathrm{n}=5)\end{array}$ & $\begin{array}{c}\mathrm{D}(600 \mu \mathrm{gg} / \mathrm{Kg}) \\
(\mathrm{n}=5)\end{array}$ \\
\hline Peso corporal $(\mathrm{g})$ & $480,6 \pm 29,8$ & $455,4 \pm 71,5$ & $520,8 \pm 32,5$ & $521,4 \pm 51,5$ \\
Peso testicular(g) & $1,79 \pm 0,01 \mathrm{a}$ & $1,86 \pm 0,08 \mathrm{a}$ & $2,04 \pm 0,09 \mathrm{~b}$ & $1,74 \pm 0,13 \mathrm{a}$ \\
Epidídimo(g) & $0,64 \pm 0,03$ & $0,66 \pm 0,04$ & $0,69 \pm 0,04$ & $0,66 \pm 0,06$ \\
IGS (\%) & $0,38 \pm 0,03 \mathrm{ab}$ & $0,42 \pm 0,06 \mathrm{a}$ & $0,39 \pm 0,03 \mathrm{ab}$ & $0,34 \pm 0,04 \mathrm{~b}$ \\
\hline
\end{tabular}

$\mathrm{n}=$ Número de animais; IGS (\%) = Índice gonadossomático. Médias seguidas por letras distintas na mesma linha diferem entre si $(\mathrm{P}<0,05)$.

Tabela 2. Peso líquido do testículo, parâmetros biométricos do parênquima testicular, população de células de Sertoli, produção espermática diária por testículo e por grama de testículo de ratos Wistar adultos, controle e tratados com diferentes doses de Ivermectina

\begin{tabular}{lcccc}
\hline \multirow{2}{*}{ Características } & \multicolumn{4}{c}{ Grupos experimentais } \\
\cline { 2 - 5 } & $\begin{array}{c}\mathrm{A}(\text { controle }) \\
(\mathrm{n}=5)\end{array}$ & $\begin{array}{c}\mathrm{B}(200 \mu \mathrm{g} / \mathrm{kg}) \\
(\mathrm{n}=5)\end{array}$ & $\begin{array}{c}\mathrm{C}(400 \mu \mathrm{g} / \mathrm{kg}) \\
(\mathrm{n}=5)\end{array}$ & $\begin{array}{c}\mathrm{D}(600 \mu \mathrm{gg} / \mathrm{kg}) \\
(\mathrm{n}=5)\end{array}$ \\
\hline Peso líquido do testículo $(\mathrm{g})$ & $1,68 \pm 0,01 \mathrm{a}$ & $1,75 \pm 0,08 \mathrm{ab}$ & $1,91 \pm 0,09 \mathrm{~b}$ & $1,63 \pm 0,13 \mathrm{a}$ \\
Diâmetro tubular & $291,6 \pm 14,0$ & $310,9 \pm 27,6$ & $304,3 \pm 13,6$ & $300,7 \pm 35,6$ \\
Altura do epitélio seminífero & $94,7 \pm 13,4 \mathrm{a}$ & $80,3 \pm 19,7 \mathrm{ab}$ & $69,4 \pm 6,9 \mathrm{~b}$ & $62,9 \pm 6,3 \mathrm{~b}$ \\
Comprimento total de TS (m) & $21,6 \pm 2,5 \mathrm{a}$ & $20,2 \pm 3,9 \mathrm{ab}$ & $24,9 \pm 2,3 \mathrm{~b}$ & $21,8 \pm 3,2 \mathrm{ab}$ \\
PED/testículo $\left(\mathrm{x} 10^{6}\right)$ & $30,5 \pm 5,9 \mathrm{a}$ & $25,0 \pm 12,7 \mathrm{a}$ & $39,4 \pm 4,7 \mathrm{~b}$ & $34,4 \pm 5,3 \mathrm{ab}$ \\
PED/g testículo $\left(\mathrm{x} 10^{6}\right)$ & $18,1 \pm 3,4$ & $14,4 \pm 7,6$ & $20,6 \pm 2,8$ & $21,1 \pm 2,4$ \\
População de CS/test $\left(\mathrm{x} 10^{6}\right)$ & $71,3 \pm 14,6 \mathrm{ab}$ & $62,9 \pm 10,4 \mathrm{a}$ & $81,5 \pm 10,6 \mathrm{~b}$ & $71,8 \pm 5,8 \mathrm{ab}$ \\
População de CS/g/test $\left(\mathrm{x} 10^{6}\right)$ & $43,3 \pm 8,0 \mathrm{a}$ & $36,3 \pm 7,4 \mathrm{~b}$ & $42,6 \pm 5,8 \mathrm{a}$ & $44,2 \pm 4,6 \mathrm{a}$ \\
\hline
\end{tabular}

$\mathrm{n}=$ Número de animais; $\mathrm{TS}=$ túbulo seminífero; $\mathrm{PED}=$ produção espermática diária; $\mathrm{CS}=$ Célula de Sertoli. Médias seguidas por letras distintas na mesma linha diferem entre si $(\mathrm{P}<0,05)$.

Foi observado maior comprimento $(\mathrm{P}<0,05)$ total de túbulo seminífero nos animais tratados com $400 \mu \mathrm{g} / \mathrm{kg}$ de ivermectina em relação ao grupo controle (Tab. 2). Segundo França e Russell (1998) e França et al. (2000), essa característica tem correlação direta e significativa com os pesos bruto e líquido dos testículos, a população de célula de Sertoli e a produção espermática diária. Por conseguinte, não se pode atribuir o maior comprimento tubular nos animais do grupo $\mathrm{C}$ à administração de ivermectina, uma vez que, nesta espécie, essas características são definidas principalmente no período pré-natal e nos primeiros 21 dias de vida, coincidindo com a 
fase de definição da população da célula de Sertoli (Orth, 1982; Orth et al., 1988). Da mesma forma, o comprimento total de túbulo seminífero observado nos ratos do grupo-controle $(21,6 \pm 2,5)$ é semelhante ao descrito por Ghosh et al. (1992), em ratos Sprague-Dawley adultos com peso testicular de $1,63 \pm 0,04 \mathrm{~g}$ e $21,8 \pm 0,6$ metros de túbulo seminífero. Isso demonstra que os animais tratados com ivermectina estão dentro do padrão para a espécie.

A produção espermática diária por testículo (PED/testículo) do grupo tratado com $400 \mu \mathrm{g} / \mathrm{kg}$ de ivermectina aumentou $23,0 \%$ e $37,0 \%$ em comparação ao grupo-controle e tratado com $200 \mu \mathrm{g} / \mathrm{kg}$ de ivermectina, respectivamente. Este dado morfométrico também tem relação direta com peso bruto e líquido do testículo, comprimento total de túbulos seminíferos e população de células de Sertoli (França e Russell, 1998; França et al., 2000). Portanto, não se pode atribuir o aumento da PED/testículo ao tratamento com ivermectina.

Pelos resultados mostrados na Tab. 3, observouse que o número de células de Sertoli foi constante em todos os grupos analisados, porém nota-se tendência de aumento tanto no índice de célula de Sertoli quanto na capacidade total de suporte de célula de Sertoli, comprovada pela significância estatística $(\mathrm{P}<0,05)$ dos grupos $\mathrm{B}$ e $\mathrm{C}$ em relação ao grupo $\mathrm{A}$. Quanto ao ICS, o aumento foi significativo $(\mathrm{P}<0,05)$ apenas nos animais do grupo $\mathrm{C}$, em relação aos do grupo $\mathrm{A}$.

Observa-se aumento significativo no número de espermátides arredondadas $(\mathrm{P}<0,05)$ nos grupos tratados com 400 e $600 \mu \mathrm{g}$ de ivermectina, em relação ao grupo-controle e ao tratado com $200 \mu \mathrm{g}$. Ocorreu aumento significativo $(\mathrm{P}<0,05)$ no número de espermatócito I em pré-leptóteno no grupo $\mathrm{C}$ em relação aos grupos $\mathrm{A}$ e $\mathrm{D}$. O número de espermátides arredondadas por secção transversal de túbulo seminífero no estágio VII nos grupos experimentais variou de 75 a 85 espermátides. Esses números que estão de acordo com o resultado encontrado por Rocha et al. (1999) para esse tipo de célula germinativa em animais-controle (80 espermátides arredondadas por secção transversal de túbulo seminífero no estágio VII). Por conseguinte, os resultados encontrados neste experimento demonstram a inocuidade da ivermectina administrada nas doses de 200,400 e $600 \mu \mathrm{g} / \mathrm{kg}$ sobre o processo espermatogênico, em virtude de não haver sido constatada redução numérica de espermátides arredondadas no estágio VII.

Tabela 3. População celular corrigida* por secção transversal de túbulo seminífero de ratos Wistar adultos, controle e tratados com diferentes doses de ivermectina

\begin{tabular}{lcccc}
\hline \multirow{1}{*}{ Características } & \multicolumn{4}{c}{ Grupos experimentais } \\
\cline { 2 - 5 } & $\begin{array}{c}\mathrm{A}(\text { controle }) \\
(\mathrm{n}=5)\end{array}$ & $\begin{array}{c}\mathrm{B}(200 \mu \mathrm{g} / \mathrm{kg}) \\
(\mathrm{n}=5)\end{array}$ & $\begin{array}{c}\mathrm{C}(400 \mu \mathrm{g} / \mathrm{kg}) \\
(\mathrm{n}=5)\end{array}$ & $\begin{array}{c}\mathrm{D}(600 \mu \mathrm{g} / \mathrm{kg}) \\
(\mathrm{n}=5)\end{array}$ \\
\hline Nucléolos de CS & $13,2 \pm 1,5$ & $12,6 \pm 1,4$ & $13,1 \pm 1,3$ & $13,6 \pm 1,6$ \\
Espermatócito I em pré- & $27,9 \pm 5,1 \mathrm{a}$ & $32,1 \pm 1,7 \mathrm{ab}$ & $34,5 \pm 1,6 \mathrm{~b}$ & $31,3 \pm 1,9 \mathrm{ac}$ \\
leptóteno & & & & \\
Espermatócito I em paquíteno & $30,5 \pm 3,7$ & $28,9 \pm 2,2$ & $31,3 \pm 1,6$ & $30,6 \pm 1,3$ \\
Espermátide arredondada & $75,1 \pm 7,04 \mathrm{a}$ & $76,4 \pm 5,9 \mathrm{a}$ & $84,5 \pm 5,0 \mathrm{~b}$ & $85,3 \pm 6,0 \mathrm{~b}$ \\
CS/secção transversal de TS & $13,2 \pm 1,5$ & $12,6 \pm 1,4$ & $13,1 \pm 1,3$ & $13,3 \pm 1,5$ \\
SPDAr/secção transversal de TS & $75,1 \pm 7,04 \mathrm{a}$ & $76,4 \pm 5,9 \mathrm{a}$ & $84,5 \pm 5,0 \mathrm{~b}$ & $85,3 \pm 6,0 \mathrm{~b}$ \\
ICS & $5,7 \pm 0,3 \mathrm{a}$ & $5,3 \pm 2,4 \mathrm{ab}$ & $6,5 \pm 0,5 \mathrm{~b}$ & $6,3 \pm 0,7 \mathrm{ab}$ \\
Capac. Total de suporte da CS & $10,2 \pm 0,5 \mathrm{a}$ & $11,0 \pm 0,1 \mathrm{~b}$ & $11,5 \pm 1,0 \mathrm{~b}$ & $11,0 \pm 1,1 \mathrm{ab}$ \\
\hline
\end{tabular}

* Números corrigidos segundo a fórmula de Abercrombie (1946), modificada por Amann e Almquist (1962). n = número de animais; CS = célula de Sertoli; TS = túbulo seminífero; SPDAr = Espermátide arredondada; ICS = Índice de célula de Sertoli; Capac. $=$ Capacidade. Médias seguidas por letras distintas na mesma linha diferem entre si $(\mathrm{P}<0,05)$. 
Segundo Russell e Peterson (1984) e Sinha-Hikin et al. (1989), o ICS reflete a eficiência funcional da célula de Sertoli e a eficiência da produção espermática por unidade de área de túbulos seminíferos expressa pela relação entre o número de espermátides alongadas suportadas por essas células. Portanto, a razão celular entre o número de células de Sertoli e as espermátides arredondadas entre grupos de diferentes tratamentos pode ser usada para determinar a ocorrência de perdas celulares ocorridas em determinado estágio do ciclo do epitélio seminífero (Russell et al., 1990). Neste experimento, os resultados de capacidade de suporte das células de Sertoli em relação às espermátides arredondadas e ao número de espermátides arredondadas nos animais-controle se assemelham aos valores encontrados por Berndtson (1977) e Orth et al. (1988) para ratos, o que demonstra coerência nos achados morfométricos de contagem celular realizada no estágio VII do ciclo do epitélio seminífero, além de evidenciar que as dosagens entre 200 e $600 \mu \mathrm{g} / \mathrm{kg}$ de ivermectina não alteraram a eficiência funcional dessas células.

No processo espermatogênico, não houve efeito tóxico ou deletério devido à ivermectina. Isso se confirmou pela manutenção do rendimento intrínseco da espermatogênese e da eficiência do processo espermatogênico entre os grupos (Tab. 2 e 3), os quais são determinados, respectivamente, pelo número de espermátides por célula de Sertoli e pela produção espermática diária por grama de testículo $(\mathrm{PED} / \mathrm{g} / \mathrm{t})$.

Segundo Johnson (1995) e França e Russell (1998), a produção espermática diária por grama de testículo é utilizada como parâmetro para avaliação da eficiência da espermatogênese, que pode ser relacionada com a duração da espermatogênese, o número de células de Sertoli por grama de testículo, a capacidade de suporte da célula de Sertoli, a densidade volumétrica dos túbulos seminíferos no testículo (\%), o número de gerações de espermatogônias e a menor perda de células germinativas durante a espermatogênese.

Em ratos Wistar, a PED por grama de testículo é de aproximadamente 20 a $24 \times 10^{6}$ espermátides (Dadoune e Demoulin, 1993; Johnson, 1995).
Neste experimento, com ratos Wistar controle e tratados, a PED por grama de testículo variou de 14,4 a $21,1 \times 10^{6}$ espermátides, encontrando-se dentro do limite de erro de $25 \%$ previsto no método histométrico empregado (França e Russell, 1998). Rocha et al. (1999) utilizaram o método histométrico observaram a $\mathrm{PED} / \mathrm{g} /$ testículo $\left(14 \times 10^{6}\right)$ em ratos Wistar adultos do grupo-controle (160 dias) semelhante à encontrada para os animais do grupo tratado com $200 \mu \mathrm{g} / \mathrm{kg}$ de ivermectina. Neste experimento, os animais do grupo-controle apresentaram $\mathrm{PED} / \mathrm{g} /$ testículo de $18,1 \times 10^{6}$ espermátides que, quando comparada com a citada por Dadoune e Demoulin (1993), demonstra provável erro de $21,0 \%$ entre os valores, o que é aceitável segundo França e Russell (1998). Por outro lado, utilizando ratos adultos com 12,5 semanas de idade (91-97 dias) e tratados com diferentes dosagens de bisfenol A, Ashby et al. (2003) encontraram pelo método hemocitométrico $17,3 \times 10^{6} \mathrm{PED} / \mathrm{g} /$ testículo nos animais-controle, semelhante ao observado neste experimento com ratos Wistar adultos. Portanto, estes dados morfométricos estão dentro dos padrões de normalidade para a espécie, além de confirmar que a eficiência do processo espermatogênico não sofreu interferência quando foram administradas diferentes doses de ivermectina.

A histologia qualitativa também confirma a ausência de efeito tóxico de doses crescentes de ivermectina $(200,400$ e $600 \mu \mathrm{g} / \mathrm{kg})$ sobre o parênquima testicular de ratos adultos, pois não se constatou degeneração de espermátides, presença de células gigantes multinucleadas resultantes da fusão de várias espermátides, espermatogônias com o citoplasma vacuolizado e com o núcleo picnótico (Fig. 1 a 4). Segundo Russell et al. (1990), o processo espermatogênico pode ser reduzido por interrupção do padrão de divisões das células tronco, degeneração e fagocitose das células germinativas, retardo na espermatogênese e descamação das células germinativas, que podem ocorrer isoladamente ou em associação no parênquima testicular por privação hormonal ou efeito tóxico de substâncias químicas. Neste experimento, os achados histopatológicos qualitativos corroboram os dados quantitativos do parênquima testicular. 


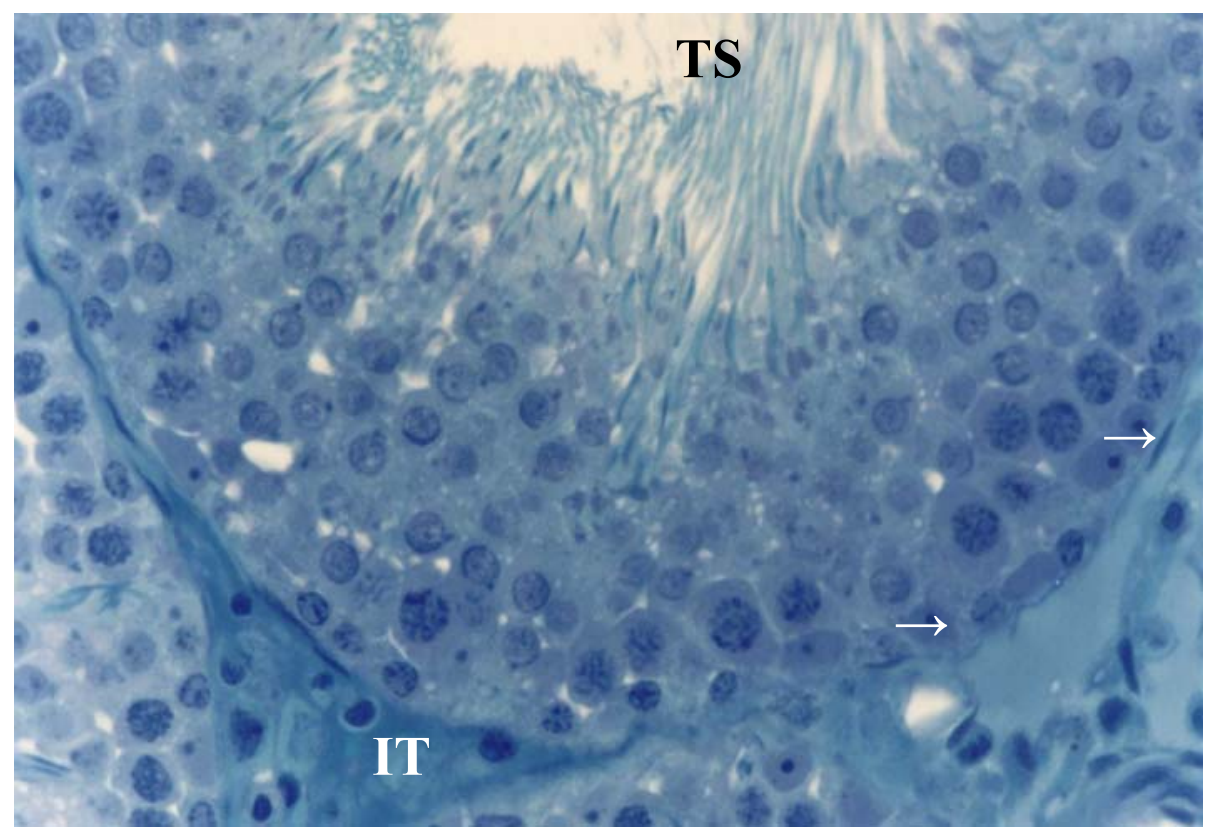

Figura 1. Testículo de rato Wistar adulto. Secção de túbulos seminíferos em animais-controles no estágio VII do epitélio seminífero. Azul de toluidina. Aumento de 400X. Túbulo seminífero (TS); interstício testicular (IT); célula de Sertoli (seta).

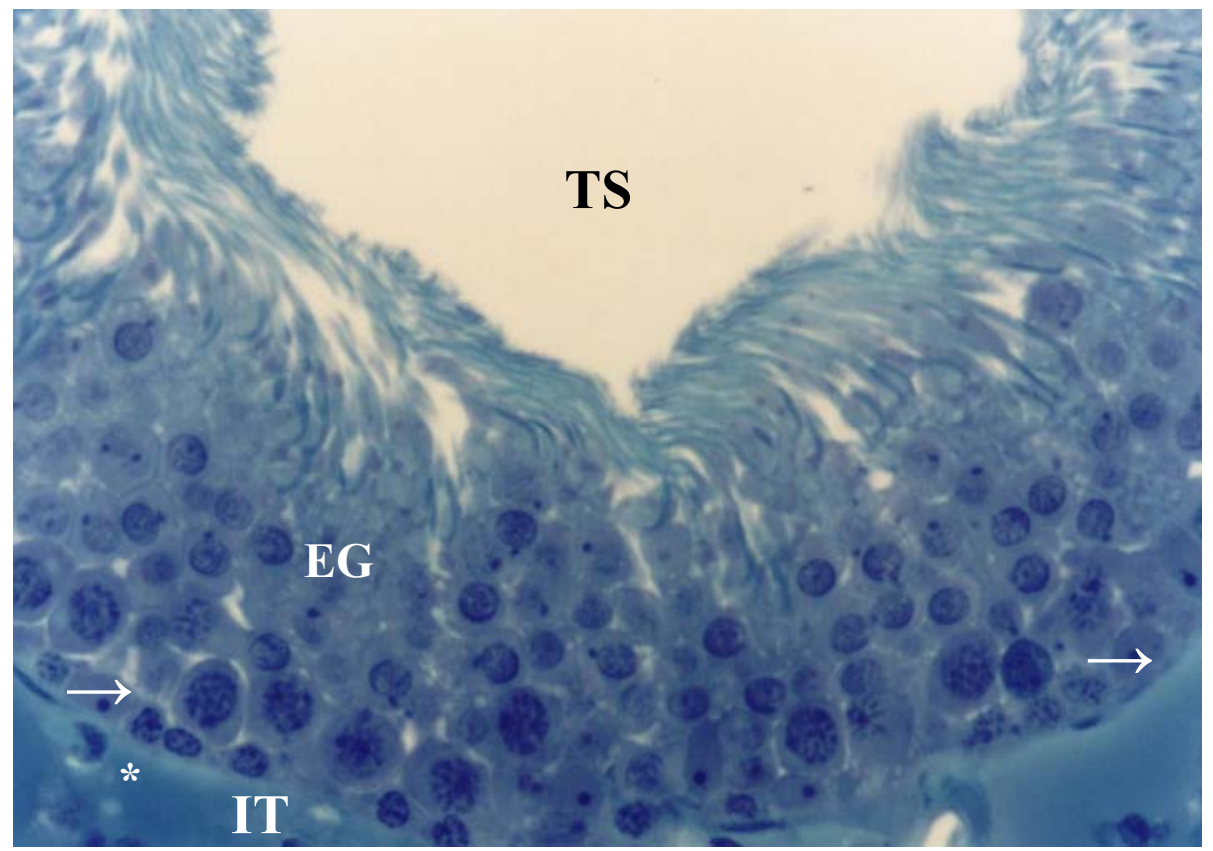

Figura 2. Testículo de Rato Wistar adulto. Secção de túbulo seminífero em animal tratado com $200 \mu \mathrm{g}$ de ivermectina/ $\mathrm{kg}$ de peso corporal, no estágio VII do ciclo do epitélio seminífero. Notar ausência de degeneração das células do epitélio germinativo (EG) e dos componentes do interstício testicular (IT). Azul de toluidina. Aumento de 400X. Túbulo seminífero (TS); célula de Sertoli (seta); célula Leydig (*). 


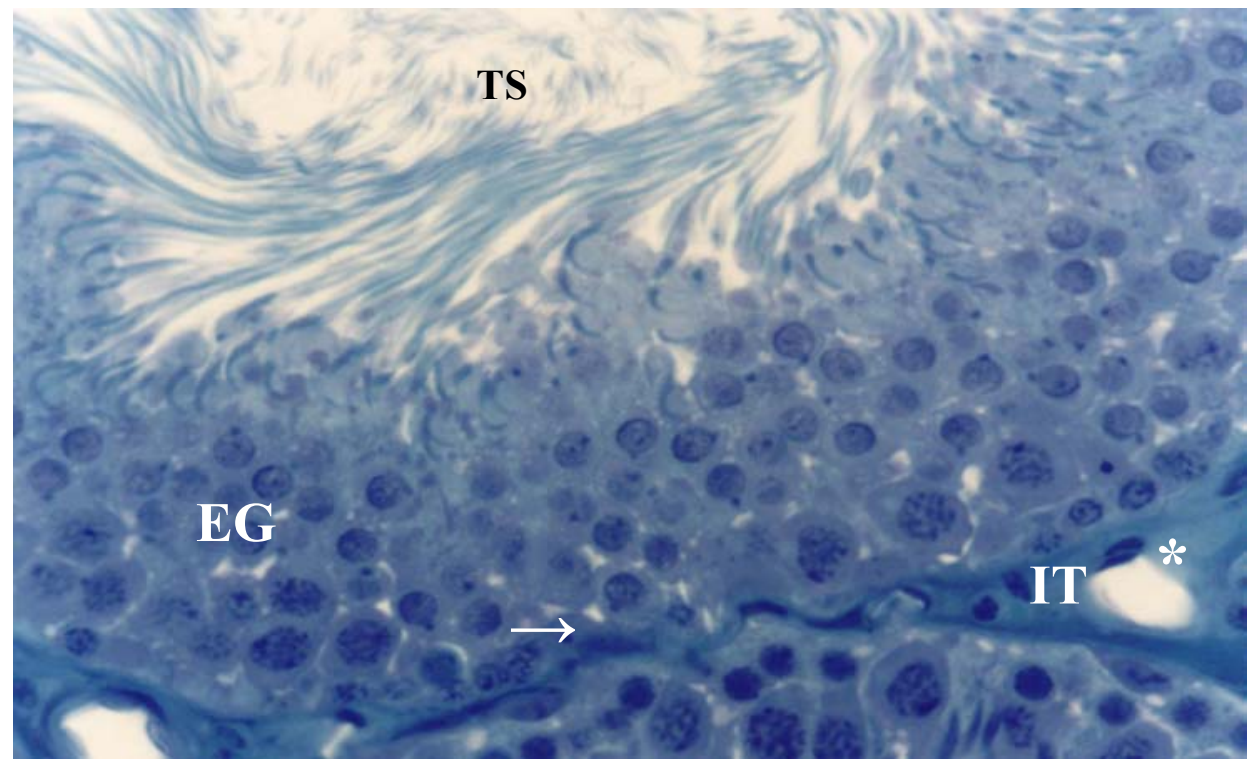

Figura 3. Testículo de rato Wistar adulto. Observar secções de túbulos seminíferos em animais tratados com $400 \mu \mathrm{g}$ de ivermectina $/ \mathrm{kg}$ de peso corporal, no estágio VII do ciclo do epitélio seminífero. Notar ausência de degeneração das células do epitélio germinativo (EG) e dos componentes do interstício testicular (IT). Azul de toluidina. Aumento de 400X. Túbulo seminífero (TS); interstício testicular (IT); célula de Sertoli (seta); célula Leydig (*).

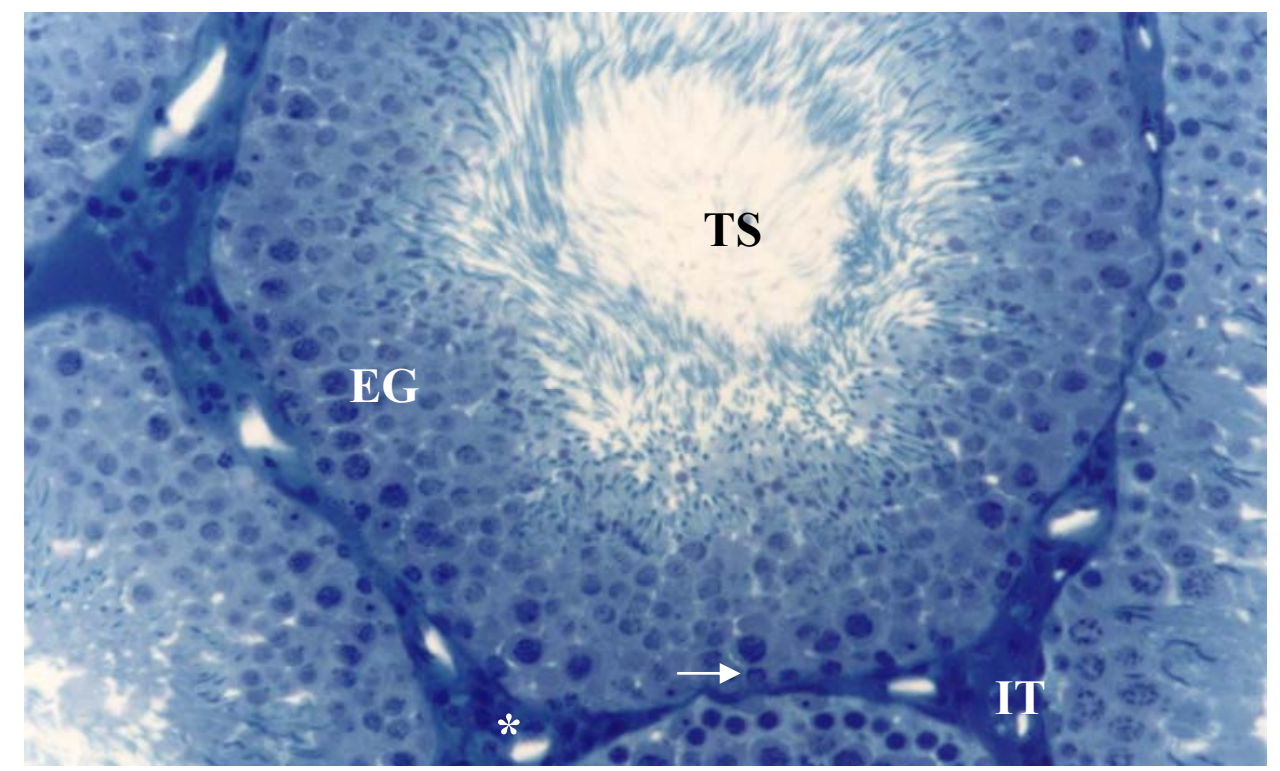

Figura 4. Testículo de rato Wistar adulto. Observar secções de túbulos seminíferos em animais tratados com $600 \mu \mathrm{g}$ de ivermectina/kg de peso corporal, no estágio VII do ciclo do epitélio seminífero. Notar ausência de degeneração das células do epitélio germinativo (EG) e dos componentes do interstício testicular (IT). Azul de toluidina. Aumento de 200X. Túbulo seminífero (TS); interstício testicular (IT); célula de Sertoli (seta); Célula Leydig (*). 
Em relação às características volumétricas do parênquima testicular (Tab. 4), o volume do epitélio seminífero $(\mathrm{ml})$ nos animais do grupo $\mathrm{C}$ foi $15 \%$ maior em relação aos do grupo $\mathrm{D}$. O mesmo ocorreu com o volume de túbulo seminífero $(\mathrm{ml})$ cujo aumento foi de $13 \%$ nos ratos do grupo $\mathrm{C}$ em relação aos do grupo- controle e do grupo tratado com $600 \mu \mathrm{g} / \mathrm{kg}$ de ivermectina. $\mathrm{O}$ volume de túbulo seminífero encontrado por Ghosh et al. (1992) em ratos adultos foi de $1,4 \mathrm{ml}$, o que confirma os resultados deste experimento.

Tabela 4. Características volumétricas do parênquima testicular $(\mathrm{ml})$ em testículos de ratos Wistar controle e tratados com diferentes doses de ivermectina aos 90 dias de idade

\begin{tabular}{lcccc}
\hline \multirow{2}{*}{ Volume } & \multicolumn{4}{c}{ Grupos experimentais } \\
\cline { 2 - 5 } & $\begin{array}{c}\mathrm{A}(\text { controle }) \\
(\mathrm{n}=5)\end{array}$ & $\begin{array}{c}\mathrm{B}(200 \mu \mathrm{g} / \mathrm{kg}) \\
(\mathrm{n}=5)\end{array}$ & $\begin{array}{c}\mathrm{C}(400 \mu \mathrm{g} / \mathrm{kg}) \\
(\mathrm{n}=5)\end{array}$ & $\begin{array}{c}\mathrm{D}(600 \mu \mathrm{g} / \mathrm{kg}) \\
(\mathrm{n}=5)\end{array}$ \\
\hline Célula de Leydig & $0,02 \pm 0,01$ & $0,01 \pm 0,01$ & $0,02 \pm 0,01$ & $0,01 \pm 0,01$ \\
Epitélio seminífero & $1,24 \pm 0,09 \mathrm{ab}$ & $1,29 \pm 0,09 \mathrm{ab}$ & $1,42 \pm 0,03 \mathrm{~b}$ & $1,20 \pm 0,13 \mathrm{a}$ \\
Lume & $0,13 \pm 0,02$ & $0,17 \pm 0,09$ & $0,19 \pm 0,04$ & $0,18 \pm 0,03$ \\
Túnica própria & $0,04 \pm 0,01$ & $0,03 \pm 0,01$ & $0,03 \pm 0,005$ & $0,03 \pm 0,01$ \\
Túbulo seminífero & $1,43 \pm 0,08 \mathrm{a}$ & $1,50 \pm 0,07 \mathrm{ab}$ & $1,65 \pm 0,04 \mathrm{~b}$ & $1,42 \pm 0,11 \mathrm{a}$ \\
Cel. do conjuntivo & $0,006 \pm 0,002$ & $0,005 \pm 0,002$ & $0,004 \pm 0,001$ & $0,003 \pm 0,002$ \\
Vaso & $0,09 \pm 0,02$ & $0,10 \pm 0,03$ & $0,14 \pm 0,03$ & $0,09 \pm 0,03$ \\
Espaço linfático & $0,08 \pm 0,03$ & $0,08 \pm 0,03$ & $0,10 \pm 0,05$ & $0,09 \pm 0,03$ \\
\hline
\end{tabular}

$\mathrm{n}=$ número de animais. Médias seguidas por letras distintas na mesma linha diferem entre si $(\mathrm{P}<0,05)$.

Os resultados das avaliações morfométricas quantitativas e qualitativas do processo espermatogênico, assim como a estrutura do parênquima testicular possibilitam afirmar que os ratos Wistar adultos submetidos a diferentes doses de ivermectina por via subcutânea não apresentaram perda de eficiência funcional das células de Sertoli e da produção espermática por unidade de área de túbulos seminíferos. A administração subcutânea de ivermectina nas dosagens estudadas $(200,400$ e $600 \mu \mathrm{g} / \mathrm{kg})$ não influenciou no rendimento intrínseco da espermatogênese nem provocou efeitos indesejáveis sobre o parênquima testicular e o processo espermatogênico.

\section{AGRADECIMENTOS}

Ao Conselho Nacional de Desenvolvimento Científico e Tecnológico $(\mathrm{CNPq})$ pela concessão de bolsa de estudo durante a realização do mestrado.

\section{REFERÊNCIAS BIBLIOGRÁFICAS}

ABERCROMBIE, M. Estimation of nuclear populations from microtome sections. Anatom. Rec., v.94, p.238-248, 1946.
AMANN, R.P.; ALMIQUIST, J.O. Reproductive capacity of dairy bulls. VIII. Direct and indirect measurement of testicular sperm production. $J$. Dairy Sci., v.45, p.774-7841, 1962.

ASHBY, J.; TINWELL, H.; LEFEVRE, P.A.; JOINER, R.; HASEMAN, J. Effect on sperm production in adult Sprague-Dawley rats exposed by gavage to Biphenol A between postnatal days 91-97. Toxicol. Sci., v.74, p.129-138, 2003.

BAUMANS, V.; HAVENAAR, R.; VAN $\mathrm{HUCH}, \mathrm{H}$. The effectiveness of Ivomec and Neguvon in the control of murine mites. Lab. Anim. Sci., v.22, p.243-245, 1988.

BERNDSTSON, W.E. Methods for quantifying mammalian spermatogenesis: a review. J. Anim. Sci., v.44, p.818-833, 1977.

CUPP, E.W.; BERNARDO, M.J.; KISZEWSKI, A.E. et al. Effects of ivermectina on transmission of Onchocerca volvulus. Science, v.231, p.740$742,1986$.

DAUDONE, J.P.; DEMOULIN, A. Structure and functions of the testis. In: THIBAULT, C.; LEVASSEUR, M.; HUNTER, R. H. F. (Ed.) Reproduction in mammals and man. (Ed.) Paris: Ellipses, 1993. p.227-250. 
FLECKNELL, P.A. Rats and mice. In: Manual of Exotic Pets, 2 ed., Barcelona: Ed. British Small Animal Veterinary Association, 1994. p.83-95.

FRANÇA, L.R.; RUSSEL, L.D. The testis of domestic mammals. In: . Male reproduction; a multidisciplinary overview. Madrid: Churchill Communications Europe, 1998. p.198-219.

FRANÇA, L.R.; SILVA JR., V.A.; CHIARINIGARCIA, H.; GARCIA, S.K.; DEBELJUK, L. Cell proliferation and hormonal changes during postnatal development of the testis in the pig. Biol. Reprod., v. 63, p. 1629-1636, 2000.

GHOSH, S.; BARTKE, A.; GRASSO, P. et al. Structural manifestation of the rat Sertoli cell to hypophysectomy: a correlative morphometric and endocrine study. Endocrinology, v.131, p.485-497, 1992.

GREENE, B.M.; TAYLOR, H.G.; CUPP, E.W. et al. Comparison of ivermectina and diethylcarbamazine in the treatment of onchocerciasis. New England. J. Med., v. 313, p.133-138, 1985.

HARKNESS, J.E.; WAGNER, J.E. Biologia e Manejo. In:_ Biologia e clínica de roedores. São Paulo: Livraria Roca. 1993. p.955.

JOHNSON, L. Efficiency of spermatogenesis. Microsc. Res. Tech. 1, v.32, p.385-422,1995.

KASS, I.S.; STRETTON, A.O.W.; WANG, C.C. The effects of avermectin and drugs related to acetylcholine and 4-aminobutyric acid on neurotransmission in Ascaris suum. Molec. Biochem. Parasitol., v.13, p.213-255, 1984.

KASS, I.S.; WANG, C.C.; WALROND, J.P. et al. Avermectin $B_{1 a}$, a paralazing anthelmintic that affects interneurons and inhibitory motoneurons in Ascaris. Proc. Natn. Acad. Sci., v.77, p.6211$6215,1980$.

LANKAS, G.R.; MINSKER, D.H.; ROBERTSON, R.T. Effects of ivermectin on reproduction and neonatal toxicity in rats. $F d$ Chem Toxic, v.27, p.523-529, 1989.
MARQUES, M.A.P. Controle parasitológico. In: Animais de laboratório - criação $e$ experimentação. Rio de Janeiro: Ed. FioCruz, 2002. p.333-315.

NESSEL, R.J.; JACOB, T.A.; ROBERTSON, R.T. Recent developments in the control of the Animal Parasites. Rajway: Merck \& Co., 1983. p.98-10.

ORTH, J.M. Proliferation of Sertoli cells in fetal and postnatal rats: a quantitative autoradiographic study. Anatom. Rec., v.203, p.485-492, 1982.

ORTH, J.M.; GUNSAWS, G.L.; LAMPERTI, A.A. Evidence from Sertoli cell-depleted rats indicates that spermatid number in adults depends on numbers of Sertoli cells produced during perinatal developmente. Endocrinology, v.122, p.787-794, 1988.

REIS, J.C. Estatística Aplicada à Pesquisa em Ciência Veterinária. Olinda: Luci Artes Gráficas Ltda., 2003. 615 p.

ROCHA, D.C.M.; DEBELJUK, L.; FRANÇA, L.R. Exposure to constant light during testis development increase daily sperm production in adult Wistar rats. Tissue \& Cell, v.31, p.372-379, 1999.

RUSSEL, L.D.; ETTLIN, R.A.; SINHA HIKIN, A. P. et al. Histological and histopathological evaluation of the testis. Bolesta: Cache River Press, 1990. 289 p.

RUSSELL, L.D.; FRANÇA, L.R. Building a testis. Tissue \& Cell, v.27, p.129-147, 1995.

RUSSELL, L.D.; PETERSON, R.N. Determination of the elongate spermatid-Sertoli cell ratio in various mammals. J. Reprod. Fertil., v.70, p.635-641, 1984.

SINHA-HIKIN, A.P.; AMADOR, A.G.; KLEMCKE, H. G. et al. Correlative morphology and endocrinology of Sertoli cells in hamster teste sin active and inative states of spermatogeneses. Endocrinology, v.125, p.18291843, 1989. 